Research Article

\title{
Histological, Biochemical and DNA Changes in the Liver of Male Albino Rats Treated with Silver Nanoparticles
}

\author{
Abed Hassan Baraaj \\ Department of Biology, Collage of Sciences-University of Baghdad, Baghdad, Iraq. \\ \Corresponding author. E-mail: abed.hassan20@yahoo.com
}

Received: May 19, 2020; Accepted: Aug. 28, 2020; Published: Nov. 2I, 2020

Citation: Abed Hassan. Baraaj, Histological, Biochemical and DNA Changes in the Liver of Male Albino Rats Treated with Silver Nanoparticles. Nano Biomed. Eng., 202I, I3(I): 20-26.

DOI: 10.5101/nbe.v13i1.p20-26.

\begin{abstract}
Sliver nanoparticles (Ag NPs) are produced industrially and commercially available in recent time. Silver and its nanoparticles are widely applied to consuming medical purposes. Silver nanoparticles are able to resemble cellular components and typical proteins, which helps the nanoparticles to cross natural barriers in human body. For this reason, the current study was designed to investigate the damage caused by silver nanoparticles, especially in liver which is one of the most targeted organs of nanoparticles as a result of their accumulation and damages caused in various aspects such as tissue, functional ability and DNA of liver cells. 30 albino male rats were used for this study and were divided into 3 main groups. The first group represented control and a normal saline solution was given, while the second group was given silver nanoparticles at a concentration of $2 \mathrm{mg} / \mathrm{kg}$ of body weight, and the third group was given silver nanoparticles at a concentration of $3 \mathrm{mg} / \mathrm{kg}$ of body weight. Each concentration of Ag NPs was dissolved in $3 \mathrm{~mL}$ of the normal saline and given directly to the experimental animal's stomach by feeding tube with diameter of $0.6 \mathrm{~cm}$ and every day for 10 weeks. The results in the current study showed histopathological change in liver tissue such as large granulomatous lesion with an increase in macrophage numbers, as also shown by necrotic hepatocytes with dilation of sinusoids. The deformation of architecture in the parenchyma appeared in both concentrations. The biochemical parameters investigation in the liver clarified increased level of enzymes accordance with doses of Ag NPs. The damage was identified in DNA of hepatocytes by comet assay and the degree of damage was evident through increasing the numbers of tailed nuclei and in strand breaks of DNA. The reactive oxygen species (ROS) generation had a key role in the events of structural and functional disorders in the liver of experimental animals.
\end{abstract}

Keywords: Silver, Nanoparticles, Liver, Histopathological, Enzymes, Comet assay, DNA

\section{Introduction}

The technology that deals with structures and size of materials ranging in size from 1-100 nmnanoparticles is called nanotechnology; it has been shown that nanoparticles have a relatively higher toxicity when compared to other sizes. In addition, the different toxicity of nanoparticles is related to different sizes and shapes of nanoparticles [1]. Numerous studies and reports have been issued on the potential benefits of applying nanoparticles of silver (Ag NPs) in various areas of life, but there is a missing of Information related to health effects during home use of nanoparticles-based materials. Recent articles 
have confirmed that nanoparticles to be possible for penetrates the human body [2-4]. Nanoparticles have dimensions that make them resemble cellular components and typical proteins, which helps the nanoparticles to a cross natural barriers in human body, leading to harmful of tissues reactions [5]. Surface areas play a major role in determining the important properties of the toxic interaction of nanoparticles with in cells [6, 7]. Silver nanoparticles are one of the manufactured nanomaterials produced industrially and commercially available in recent time, silver and its nanoparticles are widely applied to consumer products and medical purposes [8]. The digestive system absorbs the nanoparticles of silver which are transferred to the liver by the hepatic portal vein and have harmful effect on the liver according to its work by conducting a preliminary examination of all the foods Absorbed by the digestive system. Before it turns into other system in the body, the nanoparticles of silver are bound with blood plasma proteins and then distributed to various organs of the body and enter the cells [3, 9]. Nanoparticles have various physical and chemical properties and interaction with cells by divergent way indirectly such as macro-pinocytosis, phagocytosis and endocytosis or directly via so-called adhesive reaction [10]. Important increase was observed in the level of liver enzymes in the blood of mice treated with silver nanoparticles due to the harmful physiological effect of these molecules when compared with control group as a result of severe irritation of the intracellular oxidation system due to the liver damage [9]. Silver nanoparticles or silver ions released from them interact with the biological system and cause oxidative stress of cells, leading to DNA damage and death of inflammatory cells [11].

\section{Experimental}

\section{The preparation of Ag NPs}

Silver nanoparticles (Ag NPs), nano powder particle size $<100 \mathrm{~nm}$ were manufactured by Sigma Aldrich Chemical Company (USA). Nano powder of silver was weighted by sensitive balance to acquire 2 doses (2 and $3 \mathrm{mg}$ ) which agreed with the body weight of experimental rats [11]. Each weight of silver powder was dissolving in $3 \mathrm{~mL}$ of physiological solution (0.09 $\mathrm{NaCl}$ ), and then given to experimental animals orally direct to the stomach via a feeding tube $(0.6 \mathrm{~cm}$ in dimeter) for 8 weeks [12].

\section{Experimental animals}

The experiment was carried out in the current study on 30 male sexually mature Sprague-Dawley albino rats (Rattus norvegicus). The weight of the experimental male rats ranged from 200-220 gm and their age at 16-17 weeks. The animals were obtained from the pharmaceutical control center in Baghdad. The animals were kept under appropriate laboratory condition and adapted to laboratory conditions for a period of 15 days from the date of their establishment. 30 male rats were used, divided into 3 main groups randomly, by 10 rats per group with dosed as follows:

Group 1: Control, rats were given orally with physiological solution $(0.09 \mathrm{NaCl})$ for 10 weeks;

Group 2: Treated with Ag NPs suspension, rats were given orally with $2 \mathrm{mg} / \mathrm{kg}$ b.w. for 10 weeks; and

Group 3: Treated with Ag NPs suspension, rats were given orally with $3 \mathrm{mg} / \mathrm{kg}$ b.w. for 10 weeks.

\section{Dealing with animals}

The experimental male rats were killed under anesthesia after completing the experiments on them. The collected blood samples werecentrifuged at 3000 rpm for $20 \mathrm{~min}$. The blood serum was kept at $-20^{\circ} \mathrm{C}$, with liver extract of each male rat.

\section{Samples prearations}

To achieve the purpose of this study, different preparations of samples wererequired for the histological, biochemical and DNA aspects to assess the extent of the harmful effect of silver nanoparticles on the hepatocytes of experimental male rats as follows.

\section{Histological preparation}

It was performed on liver samples in size $0.5 \mathrm{~cm}$ for each sample; slides were prepared and stained for histological diagnosis according to [13].

\section{Biochemical preparation}

The estimation of liver enzymes activity was conducted, including: Estimation of serum activity of alanine aminotransferase (ALT) adopting the procedure with ALT kit from Agappe Company (India); Estimation of serum activity of aspartate aminotransferase (AST) adopting the procedure with AST kit from Agappe Company (India); and 
Estimation of serum activity of alkaline phosphatase (ALP) adopting the procedure with ALP kit from Agappe Company (India).

\section{Comet assay}

To determine the amount of DNA damage in the liver cells of experimental malerats, the comet assay kit (Trevigen) was used and performed with a test according to Boeck et al. [14].

\section{Statistical analysis}

Statistical analysis of the results obtained from the experiments of this study was carried out to compare the study groups, taking into consideration the effectiveness of liver enzymes by the program of the statistical analysis system 2016. Testing was applied to analysis of variance (ANOVA). The results were expressed with mean standard deviation (Mean + S.D., statistically analyzed at a probability level less than $5 \%$ $(\mathrm{p}<0.05)$ [15].

\section{Results and Discussion}

Animals dosing ended with silver nanoparticles for 10 weeks and the following results appeared in the histopathological study.

For animals dosed with Ag NPs (2 mg/kg b.w.), the sections of liver disclosed neutrophils and mononuclear cells aggregated near the lumen of blood vessels with macrophages in liver parenchyma (Fig. 2). In addition, monocytes and neutrophils aggregated in portal area with proliferation of Kupffer cells and necrotic hepatocytes (Fig. 3), which was shown when compared with histological section of the control group liver (Fig. 1).

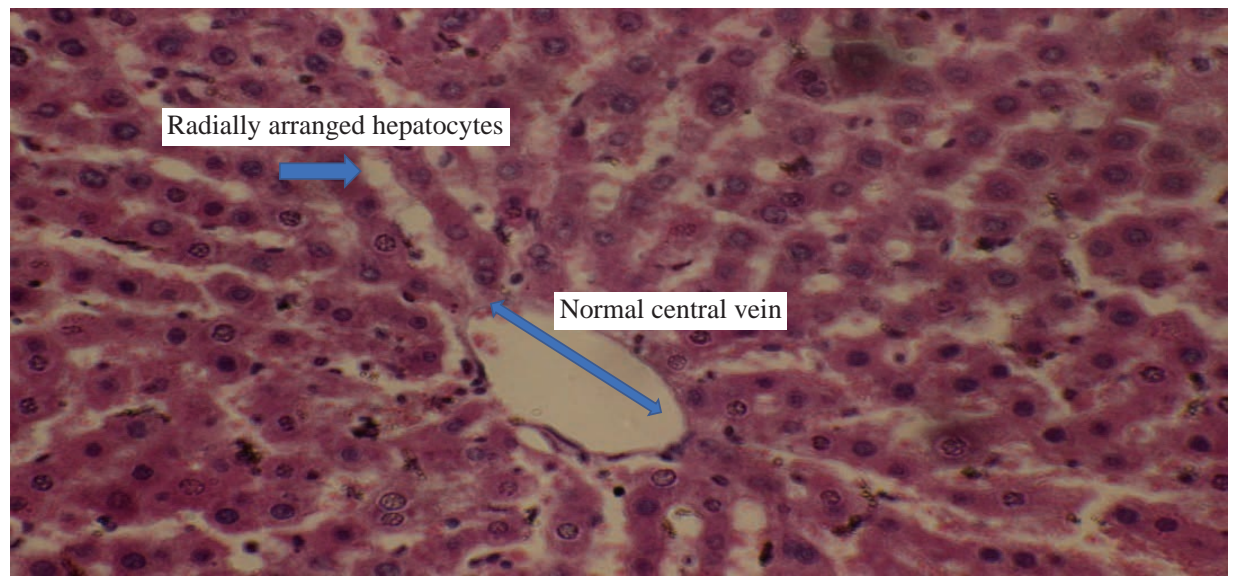

Fig. 1 Cross section in the liver of control male rats showed radially arranged hepatocytes with normal central vein (H\&E stain 40×).

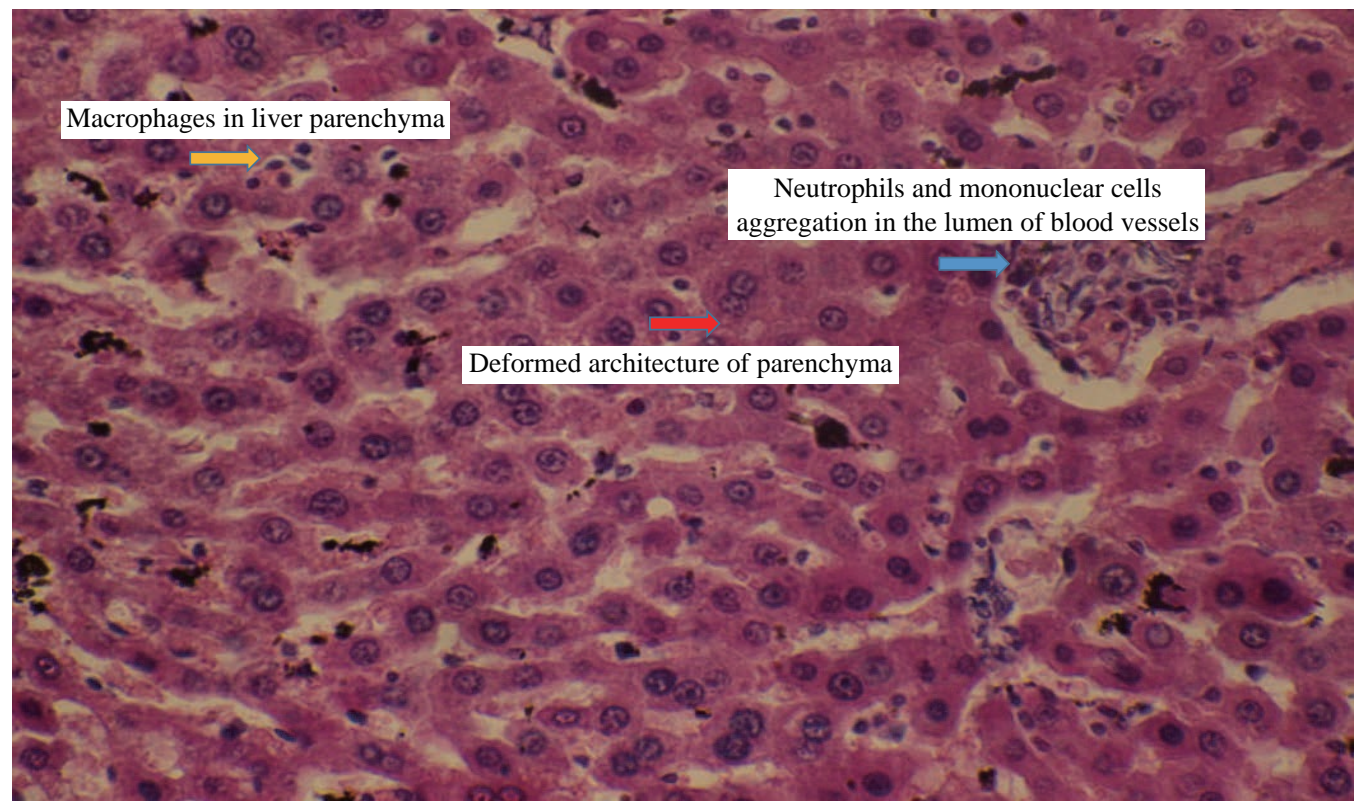

Fig. 2 Cross section in the liver of male rats treated with $2 \mathrm{mg} / \mathrm{km} \mathrm{Ag} \mathrm{NPs} \mathrm{showing} \mathrm{neutrophils} \mathrm{and} \mathrm{mononuclear} \mathrm{cells} \mathrm{aggregation}$ in the lumen of blood vessels with macrophages in liver parenchymawith deformed architecture of parenchyma (H\&E stain 40×). 


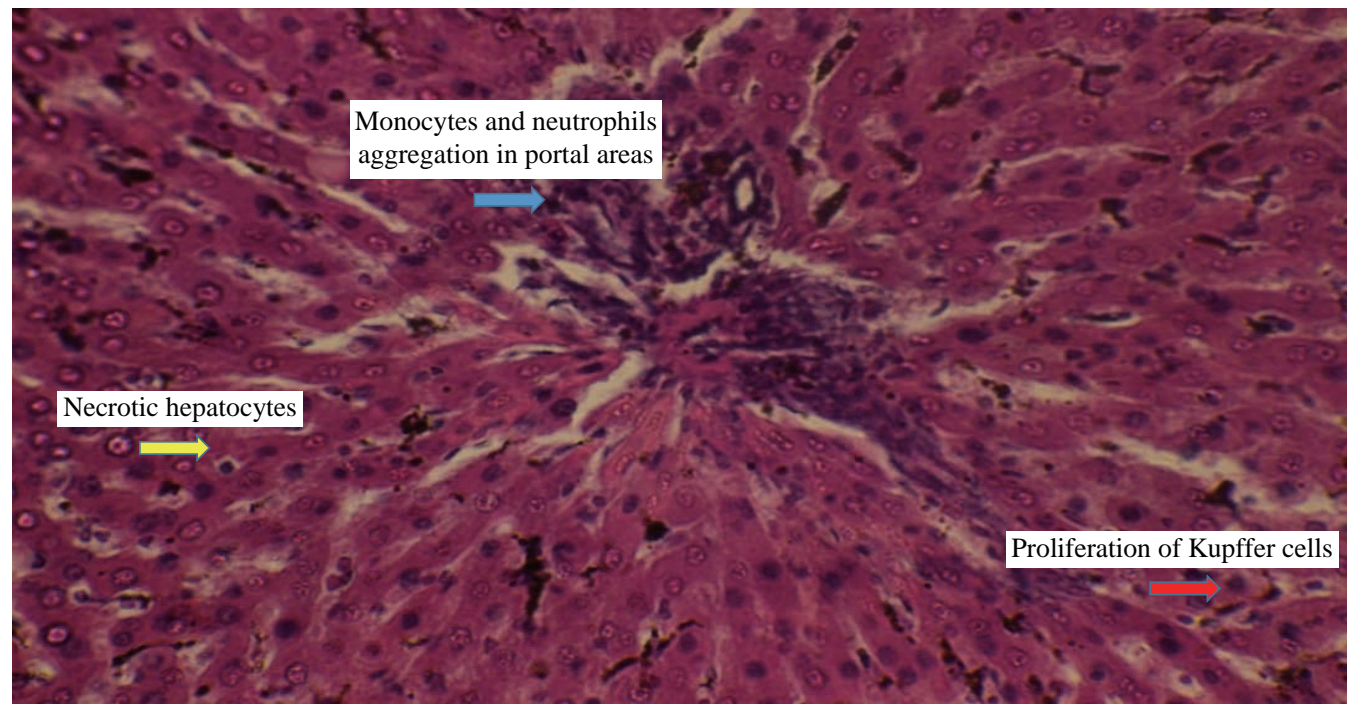

Fig. 3 Cross section in the liver of male rats treated with $2 \mathrm{mg} / \mathrm{kg}$ Ag NPs exhibiting monocytes and neutrophils aggregation in portal area with proliferation of Kupffer cells and necrotic hepatocytes (H\&E stain 40×).

For animals dosed with Ag NPs (3 mg/kg b.w.), the sections of liver exhibited granulomatous lesion in the parenchyma with necrotic hepatocytes (Fig. 4). It also showed congested blood vessels with fibrosis in portal area and dense dark brown plugs of bile in the canaliculi, as well as ballooning degeneration in the hepatocytes (Fig. 5). This study clarified that both doses caused deformed liver parenchyma architecture compared with histological sections of the control group liver (Fig. 1).

The immune system keeps the human body from harmful effects such as environmental pollutants, microbial infected and manufactured ones. The above results were consistent with previous study, pointing out that due to interacting with nanoparticles which led to immunotoxicity, phagocytosis played an important role in addressing the nanoparticles recognized treated and eliminated [16]. The present study showed the cluster of different kinds of immunity cells in liver, which was in agreement with numerous previous research, pointing out that when increasing the percentages of mononuclear cells, macrophages and neutrophils, especially in the liver when exposed to the accumulation of nanoparticles $[17,18]$, these

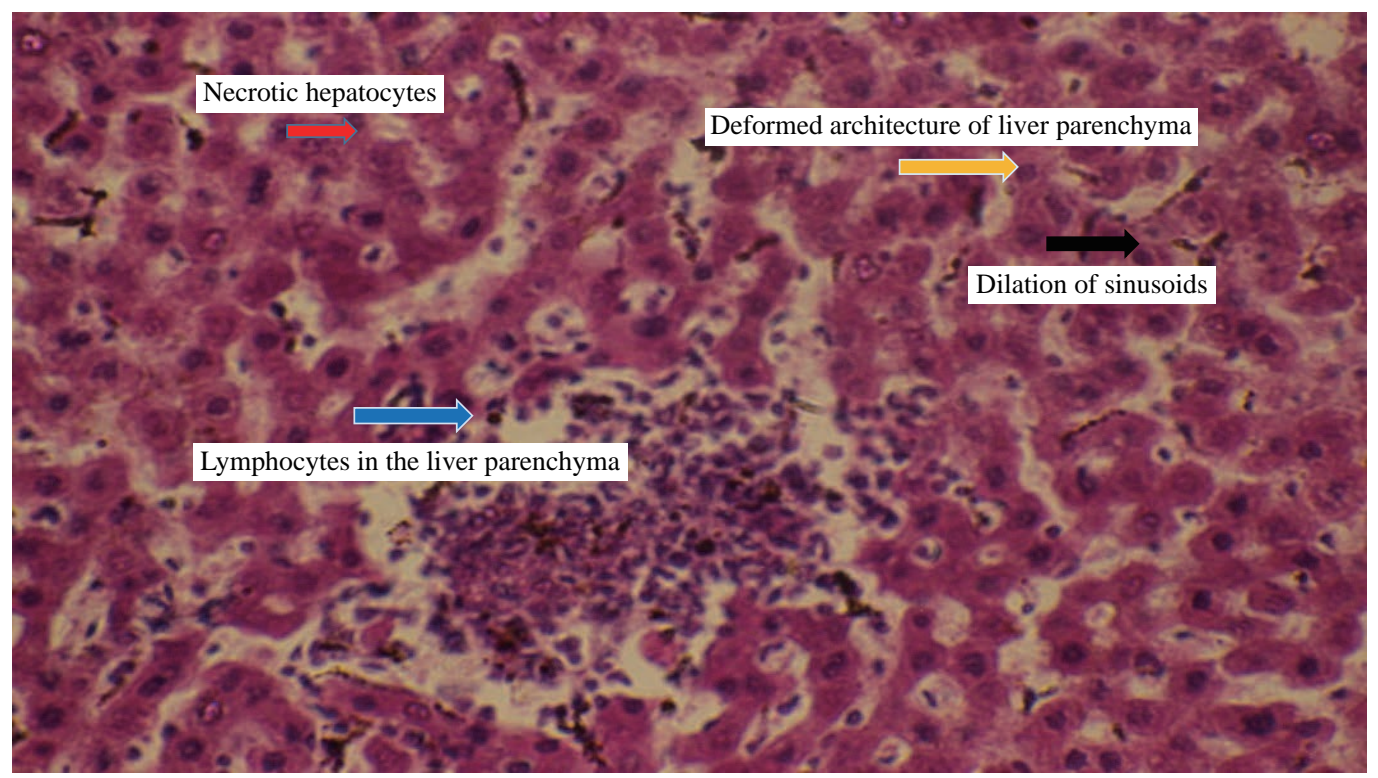

Fig. 4 Cross section in the liver of male rats treated with $3 \mathrm{mg} / \mathrm{kg}$ Ag NPs showing large granulomatous lesion consisting from aggregation of active macrophages and lymphocytes in the liver parenchyma with necrotic hepatocytes, also exhibiting deformed architecture of liverparenchyma with dilation of sinusoids (H\&E stain 40×). 


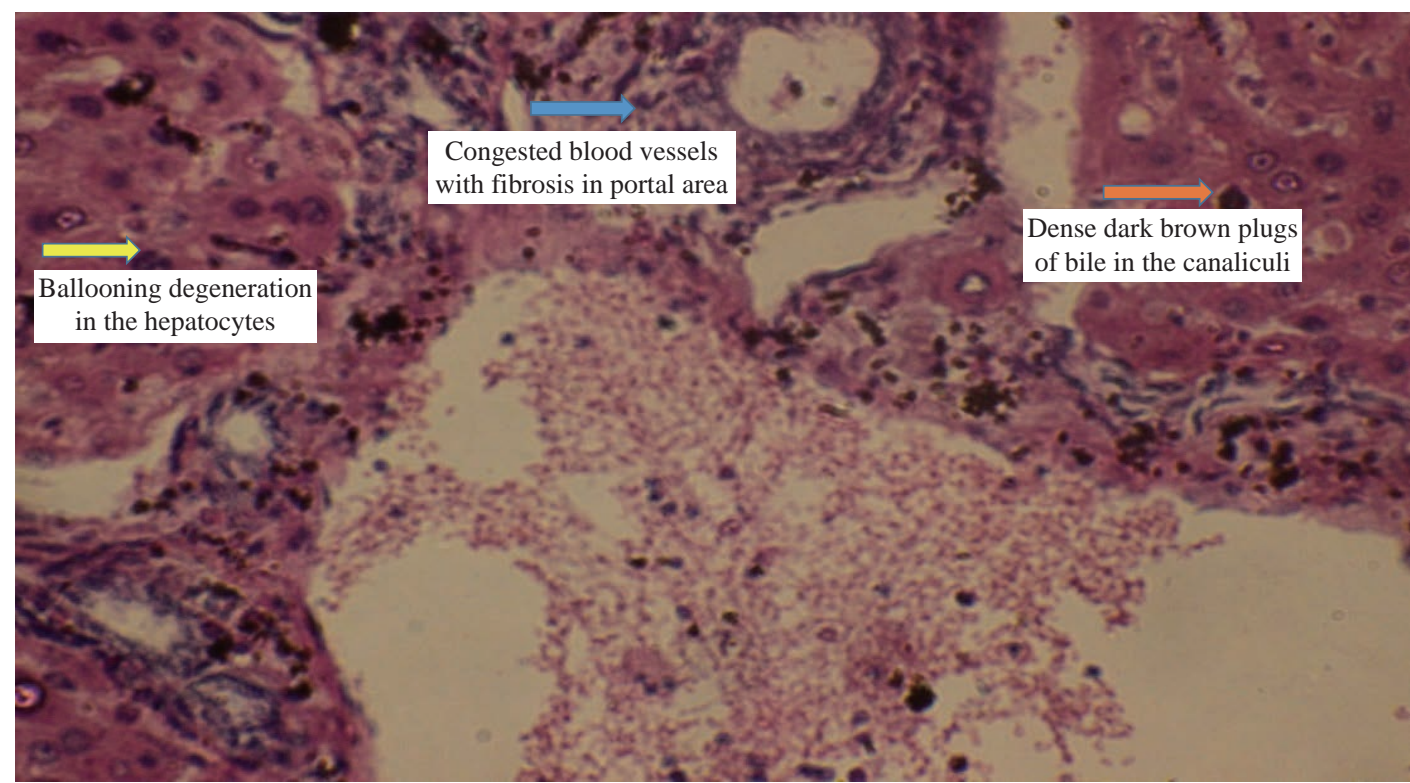

Fig. 5 Cross section in the liver of male rats treated with $3 \mathrm{mg} / \mathrm{kg} \mathrm{Ag}$ NPs exhibiting congested blood vessels with fibrosis in portal area and dense dark brown plugs of bile in the canaliculiwith ballooning degeneration in the hepatocytes (H\&E stain 40×).

cells accumulated around the blood vessels and in the parenchyma of liver exposed to nanoparticles [16]. The appearance of bile plug in this study was consistent with the result found by Shrivastava et al. [19].

\section{Biochemical study}

The result in the current study showed an increased level of liver enzymes (ALT, AST, ALP) when experimental animals are exposed to different concentrations of silver nanoparticles as shown in Table 1 , which corresponded to pathological changes in liver tissue. The liver is one of the most important organs targeted by the silver nanoparticles, accumulating in it and causing histological and functional damage to the liver [20]. The above results were in agreement with those reported by Monfared et al. [21]. For this reason, the increased level of these enzymes was an indication of the occurrence damage to the liver $[22,23]$. According to the findings by Park et al. and Lee et al. $[24,25]$, the recognized hepatotoxicity by alteration of liver function through biochemical parameters changed in blood serum of treated groups.

\section{Comet assay}

Fig. 7 shows the DNA damage in liver cells of male albino rats that were treated with silver nanoparticles in both doses for 10 weeks, and the degree of damage was evident by increasing the numbers of tailed nuclei and in strand breaks of DNA when compared with the control group (Fig. 6). The current study suggested that dealing with silver nanoparticles stimulated gene

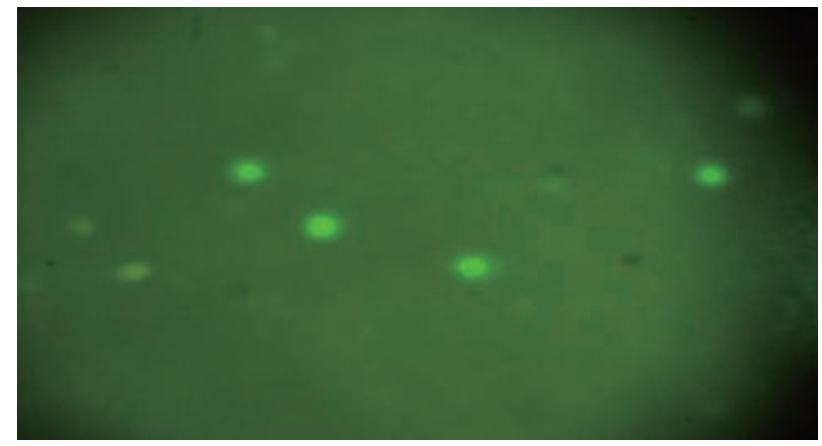

Fig. 6 Scoring categories of comet assay showing no damage in hepatocytes of the control group of male albino rats.

Table 1 Effect of Ag NPs on enzymes level of livers

\begin{tabular}{cccc}
\hline \multirow{2}{*}{ Groups treatments } & & Mean \pm SD & ALP (IU/L) \\
\cline { 2 - 4 } & ALT (IU/L) & AST (IU/L) & $200.3 \pm 10.31$ \\
Control & $31.62 \pm 3.04$ & $44.34 \pm 5.71$ & $238 \pm 10.9$ \\
Ag NPs 2 mg/kg & $41.37 \pm 4.21$ & $60.38 \pm 5.53$ & $264.32 \pm 12.95$ \\
Ag NPs 3 mg/kg & $43.21 \pm 5.91$ & $62.85 \pm 7.71$ & 18.92 \\
LSD & 2.19 & 3.20 & \\
& Significant difference $(\mathrm{p} \leq 0.05)$ between groups \\
\hline
\end{tabular}




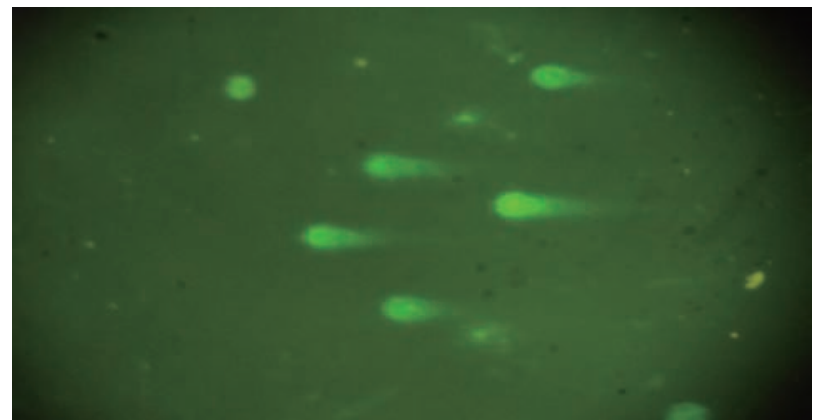

Fig. 7 Scoring categories of comet assay showing high damage increased the numbers of tailed nuclei and in strand breaks of DNA in hepatocytes of groups treated with Ag NPs of male albino rats.

mutation, necrosis, strand breaks of DNA and reactive oxygen species generation (ROS). According to previous studies, the excessive generation of reactive oxygen species caused necrosis and apoptosis [26, 27]. An increased level of ROS was connected with massive damage of DNA with necrotic increase [28, 29]. In addition, previous investigation pointed out thatsilver nanoparticles stimulated cytotoxicity and genotoxicity in cells [30], decreasing viabilityin different cells and generation of ROS causing necrosis and apoptosis by the pathway ofmitochondria [31,32] which caused lipid peroxidation on biological membranes with harmful to DNA and structure proteins [33, 34].

\section{Conclusions}

Silver nanoparticles caused damage to liver induced various histopathological changes with deformed architecture of hepatocytes, and caused alteration in the biochemical parameter of liver function such as AST, ALT and ALP. Silver nanoparticles induced DNA damage of liver through cytotoxicity effect of Ag NPs interaction with DNA. The size of Ag NPs played an important role to harm the liver because it was easily absorbed by small intestine and transferred to the liver, and then accumulated there, causing various damages in the liver of the treated groups of male albino rats. Silver nanoparticles showed the ability to induce generation of reactive oxygen species, necrosis apoptosis, cytotoxicity and genotoxicity in cells, with immune disorders also occurring.

\section{Conflict of Interests}

The authors declare that no competing interest exists.

\section{References}

[1] J.F. Hillyer, R.M. Albrecht, Gastrointestinal per sorption and tissue distribution of differently sized colloidal gold nanoparticles. J. Pharm. Sci., 2001, 90: 1927-1936.

[2] K. Dziendzi kowska, J. Gromadzka-Ostowska, A. Lankoff, et al., Time dependent biodistribution and excretion of silver nanoparticles in male wester rats. $J$. Appl. Toxicol., 2010, 32: 920-928.

[3] M. Walker, D. Parsons, The biological fate of silver ions following the use of silver-containing wound care products - a review. Int. Wound J., 2012.

[4] Z. Wang, N. Li, J. Zhao, et al., CuO nanoparticle interaction with human epithelial cells: cellular uptake location, Export and genotoxicity. Chem. Res. Toxicol., 2012, 25: 1512-1521.

[5] R. De Lima, A.B. Eabra, and N. Duran, Silver nanoparticles: brief review of cytotoxicity and genotoxicity of chemically and biogenically synthesized nanoparticles. J. Appl. Toxicol., 2012, 32: 867-869.

[6] V. Rabolli, L.C. Thomassen, F. Uwambayinema, et al., The cytotoxic activity of amorphous silica nanoparticles is mainly influenced by surface area and not by aggregation. Toxicol. Lett., 2011, 206: 197-203.

[7] S. Fraga, H. Faria, M.E. Soares, et al., Influence of the surface coating on the cytotoxicity, genotoxicity and uptake of gold nanoparticles in human HepG2 cells. $J$. Appl. Toxical., 2013, 33: 1111-1119.

[8] V. Edwards-Jones, The benefits of silver in hygiene, personal care and health care. Lett. Appl. Microbiol., 2009, 49(2): 147-152.

[9] S.W. Hoven, W.J. Peijnenburg, C.A. Herberts, et al., Nano-silver a review of available data and know Ledge gaps in human and Environmental risk assessment. Nanotoxicology, 2009, 3(2): 109-138.

[10] C. Brandenberger, C. Muhlfeld, Z. Ali, et al., Quantitative evaluation of cellular up-take and trafficking of plain and polyethylene glycol-coated gold nanoparticles. Small, 2010, 6: 1669-1678.

[11] J. Skalska, L. Struzynska, Z.D. Makarewie, et al., Toxic effects of silver nanoparticles in mammals dose a risk of neurotoxicity exist. Folianeuropathol., 2015, 53(4): 281300.

[12] A.H. Baraaj, Histological and physiological effect of Chitocal on liver, some parameters of blood and body weight in male Albino Rats. Magazine of Al-Kufa University for Biology, 2014, 6(1): 1-8.

[13] S.K. Suvarna, C. Layton. and J.D. Bancr, Histological preperationsBancroft theory and practice of histological techniques, $7^{\text {th }}$ edition. Elsevier, 2013: 233-250.

[14] M. De Boeck, N. Touil, G. De Visscher, et al., Validation and Implementation of an internal standard in comet assay. Mutat. Res., 2000, 469: 181-197.

[15] B. Rosner, Fundamentals of biostatistics. Thomson Brooks Cole, Cengage Learning, 2010: 150-151.

[16] H.H. Gustafson, D. Holt-Casper, D.W. Grainger, et al., Nanoparticles uptake: The phagocyte problem. Nano. Today, 2015, 10(4): 487-510.

[17] H.I. Herd, K.T. Bartlett, and J.A. Gustafson, Macrophage silica nanoparticle response is phenotypically dependent. Biomaterials, 2015, 53: 574-582.

[18] D.A. Kuhn, D. Vanhecke, B. Michen, et al., Different endocytic uptake mechanisms for nanoparticles in epithelial cells and macrophages. Beilstein J. Nanotechnol, 2014, 5: 1625-1636. S. Shrivastava, T. Bera, G. Singh, et al., Characterization of antiplatelet properties of silver nanoparticles. ACS Nano, 2009, 3(6): 1357-1364.

[19] J.T. Kwon, A.H. Minai-Tehrani, S.K. Wang, et al., Acute pulmonary toxicity and body distribution of inhaled 
metallic silver nanoparticles. Toxicological Research, 2012, 28(1): 25-31.

[20] A.L. Monfared, S. Soltani, Effect of silver nanoparticles administration on the liver of rainbow trout (Oncorhynchus mykiss): histological and biochemical studies. European Journal of Experimental Biology, 2013, 3(2): 285-289.

[21] N. Elyamany, H.A. Kholoussi, D.F. Raouf, et al., Nigella sativa and Aloe vera protection against doxorubicin in hepatotoxicity. J. Exp. Appl. Anim. Sci., 2016, 2(1): 1022.

[22] A. Singh, T.K. Bhat, and O.P. Sharma, Clinical Biochemistry of Hepatotoxicity. J. Clin. Toxicol., 2011, 4: 1-19.

[23] E.J. Park, E. Bae, J. Yi, et al., Repeated-dose toxicity and inflammatory responses in mice by oral administration of silver nanoparticles. Environmental Toxicology and Pharmacology, 2010, 30(2): 162-168.

[24] J.H. Lee, Y.S. Kim, K.S. Song, et al., Bio persistence of silver nanoparticles in tissues from Sprague-Dawley rats. Particle and Fiber Toxicology, 2013, 10(1): 1.

[25] P.V. Asharani, M.P. Hande, and L.S. Valiyaveetti, Antiproliferative activity of silver nanoparticles. BMC Cell Biology, 2009, 10(1): 1.

[26] S. Hackenberg, A. Scherzed, M. Kessler, et al., Silver nanoparticles evaluation of DNA damage, toxicity and functional impairment in human mesenchymal stem cells. Toxicology Letters, 2011, 201(1): 27-33.

[27] R. Foldbjerg, P. Olesen, M. Hougaard, et al., PVP-coated silver nanoparticles and silver ions induce reactive oxygen species, Apoptosis and necrosis in THP-1 monocytes.
Toxicology Letters, 2009, 192(2): 156-162.

[28] R.P. Singh, P. Ramarao, Cellular uptake, intracellular trafficking and cytotoxicity of silver nanoparticles. Toxicology Letters, 2012, 213(2): 249-259.

[29] Y. Xue, S. Zhang, Y. Huang, et al., Acute toxic effects and gender-related biokinetics of silver nanoparticles following an intravenous injection in mice. Journal of Applied Toxicology, 2012, 32(11): 890-899.

[30] R. Hess, L.Jones, and J.J. Schlager, Unique cellular Interaction of silver nanoparticles: size-dependent generation of reaction oxygen species. J. Phys. Chem. B, 2008, 112: 13608-13619.

[31] Y.H. Hsin, C.F. Chen, S. Huang, et al., The apoptotic effect of nano silver is mediated by a ROS-and JNKdependent mechanism involving the mitochondrial pathway in $\mathrm{NIH}_{3} \mathrm{~T}_{4}$ Cells. Toxicology Letters, 2008, 179(3): 130-139.

[32] W. Liu, Y. Wu, C. Wang, et al., Impact of silver nanoparticles on human cells: effect of particle size. Nanotoxicology B, 2010, 4(3): 319-330.

[33] S.H. Kim, J.W. Ko, S.K. Koh, et al., Silver nanoparticles induce apoptotic cell death in cultured cerebral cortical neurons. Molecular \&cellular Toxicology, 2014, 10(2): 173-179.

Copyright $\odot$ Abed Hassan. Baraaj. This is an open-access article distributed under the terms of the Creative Commons Attribution License, which permits unrestricted use, distribution, and reproduction in any medium, provided the original author and source are credited. 